\title{
ESTIMATION OF THE VESSEL'S SAILING RESISTANCE IN THE PRELIMINARY ANALYSES
}

\author{
Adam Charchalis \\ Gdynia Maritime University, Faculty of Marine Engineering \\ Morska Street 83, 81-225 Gdynia, Poland \\ e-mail:a.charchalis@wm.umg.edu.pl
}

\begin{abstract}
In this article is presented the methodology of calculation of principal parameters of hull a vessel and resistance components. The approximate method is based on the analysis of the results of model tests and surrender tests presented in the literature. Ship owners' preliminary assumptions for new ship consist of deadweight, speed-shipping line and others. This goal needs definition of principal dimensions of a vessel, which are the basis for further calculations of hull's resistance and evaluation of necessary power of main engine to fulfil shipping requirements. The route and its environment, type of cargo, quantity to be moved, and value of the cargo and port facilities are typical features, which will be considered when evolving the size, speed, and specification of a suitable ship. Specific service requirements will be similarly considered when evolving vessels such as warships, passenger ships or fishing vessels. Selection of main dimensions of vessel is limited by related to seaways or harbours characteristic and limitations rules regarding buoyancy, stability, hull strength, manoeuvring capability, etc. The influence of the main dimensions of the ship and their coefficients of maritime and strength properties of the ship were presented. Moreover, formulas for calculation of the ship's resistance components, such as friction resistance, and wave shape, as well as the results of calculations for different types of ships, for the assumed deadweight and speed of sailing, are presented.
\end{abstract}

Keywords: merchant vessel, hull dimensions parameters, hull coefficient, hull resistance, hull power of the vessel

List of major designations:

$\mathrm{A}_{\mathrm{M}}-$ Midship section area $\left[\mathrm{m}^{2}\right]$,

B - The waterline breadth of the hull $[\mathrm{m}]$,

$\mathrm{C}_{\mathrm{B}}=\nabla / \mathrm{LBT}-\mathrm{Block}$ coefficient,

$\mathrm{C}_{\mathrm{D}}=\mathrm{DWT} / \Delta-$ Mass coefficient,

$\mathrm{C}_{\mathrm{M}}=\mathrm{A}_{\mathrm{M}} / \mathrm{BT}-$ Midship section coefficient,

$C_{P}=\nabla / A_{m} L-$ Prismatic coefficient,

DWT - Deadweight,

F $n=v / \sqrt{g L}-$ Froude number,

Lpp - Length between perpendiculars $[\mathrm{m}]$,

$\mathrm{T}$ - The draught a midships [m],

$\mathrm{v}-$ Ship's cruising speed $[\mathrm{m} / \mathrm{s}]$,

$\nabla$ - The volumetric displacement of the hull $\left[\mathrm{m}^{3}\right]$,

$\Delta \quad$ - The mass displacement of the hull [t],

$\Omega-$ The wetted surface of the hull $\left[\mathrm{m}^{2}\right]$.

\section{Design assumptions}

A ship is a complex vehicle. Its production requires the involvement of a wide range of engineering disciplines. Ship design is not an exact science but embraces a mixture of theoretical analysis and empirical data accumulated from previous successful designs. Due to the complex interrelationships between features of the technical design, and the construction of the ship and its operation, the final ship design will often represent a compromise between opposite ship 
requirements [3]. The development of the overall ship design and its production cannot normally be treated in technical isolation, as operational requirements have to be considered. For example, the ship will often form a part of a through transport system; this may range from sophisticated container systems with dedicated ships operating between specified ports, or ferries and RO/RO vessels relying on a regular wheeled through cargo, to tramp vessels on non-regular schedules which rely on carrying various types of cargo between various ports.

The route and its environment, type of cargo, quantity to be moved, and value of the cargo and port facilities are typical features, which will be considered when evolving the size, speed, and specification of a suitable ship [2]. Specific service requirements will be similarly considered when evolving vessels such as warships, passenger ships or fishing vessels. Ship owners operate ships to make a satisfactory profit on their investment the evolution of a technical design can therefore be considered as a component part of an overall economic model. In evolving a ship design, it is therefore necessary to assess the operating requirements and the environment in which the vessel is to operate, to evolve the feasible technical design and to economical justify the viability of the proposal. In an overall final design process, the objectives have to be clearly identified and constraints in the process incorporated. The following discusses some of the alternative objectives [4].

\section{Limitations of ships' main dimensions}

\subsection{Restrictions resulting from the intended shipping route}

The company's assumptions, which are the basis for the ship's design, specify the main requirements for the ship's construction, its operation, and possibly the requirements for the ship's main propulsion and equipment. These assumptions refer to floating region and shipping route, type of transported cargo, adopted main propulsion type, specification of fuel used, accepted ship classification rules, etc. They influence the choice of dimensions of the main ship. The main dimensions of the ship, i.e. displacement, length, width, draught, total height depends on the assumed route of the voyage [3]. This is due to navigation limitations on the route, i.e. the dimensions of canals and locks, depth in straits or the height of clearances over water mirrors and bridges, e.g. in the Suez Channel, Danish straits or on the St. Lawrence River. Tab. 1 shows dimensional limitations of the ship's hull resulting from navigation restrictions on the assumed cruise routes.

Tab. 1. Some limitations of shipping routes

\begin{tabular}{|l|c|c|c|c|c|}
\hline & $\mathrm{B}[\mathrm{m}]$ & $\mathrm{T}[\mathrm{m}]$ & $\mathrm{L}[\mathrm{m}]$ & $\begin{array}{c}\text { Max. height of } \\
\text { freeboard [m] }\end{array}$ & Comments \\
\hline Kiel Canal & 40 & 9.5 & 315 & & \\
\hline Danish Straits & 48 & 15 & 260 & 65 & \\
\hline Panama Canal & 32.2 & 12.04 & 289.5 & & \\
\hline Post Panama Canal & 54 & 18.29 & 426 & & \\
\hline New Suez Canal & 50 & 20.12 & & 68 & $\begin{array}{c}\text { Wetted area limit BT } \\
\text { to } 1006 \mathrm{~m}^{2}\end{array}$ \\
\hline St. Lawrence Seaway & 77.5 & 12.2 & & 57.5 & \\
\hline Malacca Straits & 23 & 7.6 & 222 & & \\
\hline
\end{tabular}

\subsection{Restrictions resulting from the assurance of appropriate marine characteristics}

The main dimensions of the ship's hull are selected due to different aspects. In ship owner assumptions, load capacity (TEU) for container vessels and deadweight (DWT) for other classes, 
and speed are given. Those values have strong impact at necessary power of the first estimate that the Naval Architect makes is to estimate the lightweight of the new ship [1].

In the lists of constructed ships, besides other basic data, the ship's deadweight is often given. On the other hand, sometimes displacement is given, which in turn is important in design calculations of hull dimensions and ship resistance.

Therefore, deadweight coefficient $C_{D}$ links the deadweight and the displacement plays an important role. This coefficient shows the extent to which the weight of the cargo and the appropriate security for its transport has a share in the total weight of the ship [1]. Deadweight includes cargo, mass of fuel, oil, fresh water, stores, crew, and effects. Cargo is the only component of deadweight, which will bring revenue; hence, other items of deadweight should be kept to a minimum. This ratio can be assessed in two variants, as a reference to the load-bearing capacity of cargo only to the displacement or global deadweight, taking into account stocks, cargo securing infrastructure, crew, etc. It is the only component of deadweight, which will bring revenue; hence, other items of deadweight should be kept to a minimum. Of course, the more extensive the transport infrastructure is, i.e. on container ships, refrigerated or passenger ships; the load-capacity factor assumes lower values.

This is one of the most important parameters showing the similarity of ship structures. The second factor of similarity of ships under construction is hull fullness factor $\mathrm{C}_{\mathrm{B}}$. This factor takes into account the ratio of the volume of the submerged part of the hull to the volume of the cuboid of dimensions L, B, T. This factor indicates the shape of the underwater part of the hull, i.e. influences the value of the ship's resistance to motion and its movement properties [2].

The shape of the underwater part of the hull is also described by a number of other dependencies, i.e. the slenderness coefficient $\frac{L}{\sqrt[3]{D}}$, major dimension coefficients $\mathrm{L} / \mathrm{B}, \mathrm{B} / \mathrm{T}, \mathrm{B} / \mathrm{H}$, fullness coefficients: midship, waterline and prismatic, etc. The underwater part of the hull is also described by a number of other dependencies. Because of the ship's displacement, the number of Froude which results from the assumed sailing speed, it is important to select appropriate main dimensions of the ship, which will ensure the requirements of longitudinal and transverse stability, buoyancy, freeboard height, manoeuvrability while ensuring appropriate costs of designing and manufacturing the ship $[2,7]$.

To have a general view of the designed ship, we will show the most important data, as main dimensions of the hull, block, and DWT coefficient in following points of this project.

In Tab. 2 are presented relations between major coefficients of hull shape characteristic.

Tab. 2. List of coefficients describing main dimensions of a ship

\begin{tabular}{|c|c|c|c|c|c|c|c|}
\hline & $\mathrm{C}_{\mathrm{D}}$ & $\mathrm{C}_{\mathbf{B}}$ & $\mathrm{Cm}$ & $\mathrm{Cp}$ & $\mathrm{L} / \mathrm{B}$ & $\frac{B}{T}$ & $\frac{L}{\sqrt[3]{D}}$ \\
\hline Refrigerated cargo ships & $0.55-0.6$ & $0.6-0.7$ & 0.98 & 0.7 & $6-7$ & $2-2.5$ & $6.5-8.5$ \\
\hline Cargo vessels & $0.65-0.75$ & $\begin{array}{c}0.7-0.86 \\
(0.81)\end{array}$ & 0.99 & 0.79 & $6-7(6.8)$ & $\begin{array}{c}2-2.5 \\
(2.5)\end{array}$ & $5.5-6.5$ \\
\hline Ore vessels & 0.82 & 0.78 & 0.99 & 0.79 & $6-7(6.66)$ & $(2.5)$ & $5.5-6.5$ \\
\hline Large tankers & $\begin{array}{c}0.79-0.85 \\
(0.85)\end{array}$ & 0.83 & 0.99 & 0.79 & $\begin{array}{c}5.5-6.5 \\
(6.5)\end{array}$ & $(2.65)$ & $5.5-6.5$ \\
\hline Container ships & $\sim 0.6$ & $\begin{array}{c}0.58-0.65 \\
(0.61)\end{array}$ & 0.97 & 0.64 & $\begin{array}{c}5.5-6.5 \\
(6.42)\end{array}$ & $\begin{array}{c}2.3-3.6 \\
(2.4)\end{array}$ & $6.5-8.5$ \\
\hline Passenger vessels & 0.3 & 0.53 & 0.97 & 0.55 & $6.5-7.5$ & $\begin{array}{c}3-5 \\
(4)\end{array}$ & 8 \\
\hline
\end{tabular}

The values of coefficients, which were selected for calculations in the analysed example, were put in brackets. 
Table 3 shows the main dimensions of the ship and their influence on the maritime properties of the ship [6]. Attention should be paid to the significant influence of draught on the displacement of the ship during the voyage, loading and unloading. As a result of fuel and stock consumption, displacement is constantly changing, hence the conditions of cargo transport and loading of the ship's propulsion system.

Tab. 3. Primary Influence of Dimension

\begin{tabular}{|l|l|}
\hline \multicolumn{1}{|c|}{ Parameter } & \multicolumn{1}{|c|}{ Primary Influence of Dimensions } \\
\hline Lenght & $\begin{array}{l}\text { resistance, manoeuvrability, longitudinal } \\
\text { strength, seakeeping } \\
\text { transverse stability, resistance, manoeuvrability, } \\
\text { Beam }\end{array}$ \\
Depth & $\begin{array}{l}\text { longitudinal strength, transverse stability, } \\
\text { freeboard } \\
\text { displacement, freeboard, resistance, transverse }\end{array}$ \\
& stability \\
\hline
\end{tabular}

\section{Example of calculation of main dimensions and float resistance of various types of ships}

The basic size for the designed ship is its length. For the calculation of movement properties, stability, etc., the length between the perpendiculars of LPP is important.

The length is subject to navigation restrictions, i.e. the area of sailing, but this dimension can be estimated due to the permissible limitations of the relevant coefficients and ratios of the main dimensions and due to the value of Fn in order to avoid local maximum wave resistance, which has a particular impact on high-speed vessels, i.e. passenger ships and container ships. Local maximum wave resistance occurs at Fn of 0.2-0.24, and about 0.3. Global maximum resistance occurs at $\mathrm{Fn}=0.5$ [3]. Below are presented the dependencies according to which iterative methods it is possible initially to estimate the required ship length for the assumed displacement and speed of the vessel.

$$
\begin{gathered}
L=\left(\frac{D W T\left(\frac{L}{B}\right)^{2} \frac{B}{T}}{\rho \cdot C_{B} \cdot C_{D}}\right)^{1 / 3}[m], \\
\mathrm{L}=\frac{L}{\sqrt[3]{D}} \sqrt[3]{D}, \\
\mathrm{~F} n=v / \sqrt{g L} .
\end{gathered}
$$

Table 3 presents calculated values of displacement of the ship and its length for the assumed deadweight of 100000 DWT and speed of the vessel appropriate for a given class of ship.

Tab. 3 Calculated values of displacement and ship length

\begin{tabular}{|l|c|c|c|c|c|}
\hline & $\mathbf{V}[\mathbf{k n}]$ & $\mathbf{D W T}$ & $\begin{array}{c}\mathrm{D}=\mathrm{DWT} / \mathrm{Cd} \\
{\left[\mathrm{m}^{3}\right]}\end{array}$ & $\left.\begin{array}{c}D W T\left(\frac{L}{B}\right)^{2} \frac{B}{T} \\
L \cdot C_{B} \cdot C_{D}\end{array}\right)^{1 / 3}[\mathrm{~m}]$ & $\mathbf{L = \frac { L } { \sqrt [ 3 ] { \boldsymbol { D } } } \sqrt [ 3 ] { \boldsymbol { D } }}$ \\
\hline Cargo vessels & 16 & 100000 & 142857 & 274.38 & 287.51 \\
\hline Ore vessels & 16 & 100000 & 121951 & 256.76 & 272.75 \\
\hline Large tankers & 16 & 100000 & 117647 & 252.32 & 269 \\
\hline
\end{tabular}




\begin{tabular}{|l|c|c|c|c|c|} 
& & & & & \\
\hline Container ships & 26 & 100000 & 167000 & 345.7 & 357.94 \\
\hline Passenger vessels & 30 & - & 100000 & 373 & 371.32 \\
\hline
\end{tabular}

\subsection{Total resistance}

Ships resistance consist of frictional resistance, form resistance, wave-making resistance, additional resistance of appendages, air resistance, and wave breaking resistance. At preliminary stage of design most of attention is payed at hydrodynamic resistance of wetted area.

$$
\mathrm{R}_{\mathrm{T}}=\mathrm{C}_{\mathrm{T}} \rho \mathrm{v}^{2} \Omega \text {. }
$$

Coefficient of total resistance is a sum of frictional resistance coefficient $\mathrm{C}_{\mathrm{F}}$, shape resistance $\mathrm{C}_{\mathrm{K}}$ and wave making resistance $\mathrm{C}_{\mathrm{F}}$.

Frictional resistance makes $45-75 \%$ of total resistance. Top value is for cargo vessels having big block coefficient values and characterized by Froude number up to 0.17 . Together with Fn raising (speed), participation of frictional resistance for $F n=0.25$ reaches $60 \%$ of total resistance. For very fast war ships, passenger vessels or container vessels, sailing with speed characterized by $\mathrm{Fn}=0.3$, frictional resistance unlikely oversteps $45-50 \%$.

Frictional resistance coefficient depends on Reynolds number and is described by formula ITTC $-57[5]:$

$$
\mathrm{C}_{\mathrm{F}}=0.075 /(\log \mathrm{Rn}-2)^{2} \text {. }
$$

The shape factor $\mathrm{k}>0$ correcting the friction resistance of a flat plate in viscosity resistance is determined experimentally (towing the model at a very low speed) or using approximate formula, e.g. formula ITTC-72 [6]:

$$
k=0.017+\frac{20 C_{B}}{\left(\frac{L}{B}\right)^{2} \sqrt{\frac{B}{T}}}
$$

Moreover, frictional resistance must include correction factor due to constructional roughness of hull's sheet $\Delta \mathrm{C}_{\mathrm{F}}$, which value according to Schoenher is 0.0004 [7]

Wave breaking resistance is coming from transformation of part of energy of propulsion in form of energy loses due to ship's movement wave making. Created waves are surface type and one can distinguish bow waves and stern waves. In every group of waves can be distinguish transverse ones and slanting ones, wherein angles of slanting waves depends on type of ship and speed. Changes of angles of propagation can occurs in entering shallow waters, when angle is growing, also magnitude of waving goes up when depth of area diminish, and rise additional resistance. Wave making resistance because of bow waves interference has nit monotonous character. Coefficient of wave making resistance $\mathrm{Cw}$, which depends on Froude' number, can be described basing on viscous fluid formula (triple dimensional formula of Navier Stokes) in so-called computer model tanks or generated basing on classic tank test results relating on geometric similarities. In practice, model tests are carried out according to theory of models similarity, called Froude' $(F n)$ criterion which relay on that keeping constant value of En for the ship and model, resistance coefficient is to be the same. In Schneekluth method, the dimensionless residual resistance coefficient $\mathrm{cR}$ is determined by the formula $[6,8]$ :

$$
\begin{aligned}
& C_{R}=\left[0.0012\left(10 F_{n}-0.8\right)^{4}\left(10 C_{p}-3.3\right)^{2}\left(10^{3} \frac{\nabla}{L^{3}}+4\right)+0.005 \cdot 10^{3} \frac{\nabla}{L^{3}}+0.2+\right. \\
& \left.0.17\left(\frac{B}{T}-2.5\right)\right] \cdot 10^{-3} .
\end{aligned}
$$

The range of acceptable parameter values is determined by limitations: 


$$
\begin{gathered}
F n=0.17-0.30, \\
10^{3} \frac{\nabla}{L^{3}}=2-11 .
\end{gathered}
$$

The wetted area of the hull $\Omega$ can be calculated using many methods, which are based on statistical research on the built ships. Each of these methods, which are called from the names of their creators, is to a different degree complicated and is based on a number of coefficients characterizing the shape and dimensions of the ship's hull. Mumford formula is relatively simple and gives no deviating results and according to it, the calculations were carried out [4].

$$
\Omega=\mathrm{LT}\left(1.7+\mathrm{C}_{\mathrm{B}} \mathrm{B} / \mathrm{T}\right)\left[\mathrm{m}^{2}\right] .
$$

Total resistance takes form of equation:

$$
\mathrm{R}_{\mathrm{T}}=\left[\mathrm{C}_{\mathrm{F}}\left(1+\mathrm{K}_{1}\right)+\Delta \mathrm{C}_{\mathrm{F}}+\mathrm{C}_{\mathrm{R}}\right] \rho v^{2} \Omega / 2 .
$$

Tab. 4. Calculated values of ships parameters

\begin{tabular}{|c|c|c|c|c|c|c|c|c|}
\hline & $\mathrm{V}[\mathrm{kn}]$ & $10^{-9} \mathbf{R n}$ & $\mathbf{K}_{\mathbf{1}}$ & $10^{3} \mathrm{C}_{\mathrm{F}}$ & $10^{4} \mathrm{C}_{\mathrm{w}}$ & $\Omega\left[\mathrm{m}^{2}\right]$ & $\mathrm{R}_{\mathrm{T}}[\mathrm{kN}]$ & $\mathrm{N}_{\mathrm{h}}[\mathrm{kW}]$ \\
\hline Cargo vessels & 16 & 1.88 & 0.26 & 1.42 & 3,46 & 16390 & 1450 & 11940 \\
\hline Ore vessels & 16 & 1.76 & 0.25 & 1.43 & 3.78 & 14915 & 1330 & 10980 \\
\hline Large tankers & 16 & 1.73 & 0.30 & 1.43 & 4.19 & 14430 & 1347 & 11000 \\
\hline Container ships & 23 & 3.85 & 0.16 & 1.30 & 7 & 24850 & 4660 & 55000 \\
\hline Passenger vessels & 25 & 4.80 & 0.074 & 1.27 & 7.87 & 18980 & 3970 & 51000 \\
\hline
\end{tabular}

\section{Summary}

Prediction of propulsion power necessary for movement of designed ship is one of most important tasks at beginning stage of design process. That power can be estimated basin at data related to main constructional dimensions of a hull. For that reason, in the article is presented method of selection of main dimensions basing at list of similar constructions, with constraints due to required buoyancy, stability heavy sea durability, and performance, strength of a hull etc. In the article are given relations necessary for defining proper coefficients describing shape of a hull and necessary for estimation of resistance in way of regression.

\section{References}

[1] Barrass, C. B., Ship Design and Performance for Masters and Mates, Elsevier 2004.

[2] Charchalis, A., Krefft, J., Main Dimensions of the Container Vessels, Journal of Powertrain and Transport, Vol. 2, pp. 71-78, Warsaw 2009.

[3] Charchalis, A., Designing constraints in evaluation of ship propulsion power, Journal of KONES Powertrain and Transport, Vol. 1, pp. 29-34, Warsaw 2013.

[4] Charchalis, A., Dimensional constraints in ship design, Journal of KONES Powertrain and Transport, Vol. 2, pp. 27-32, Warsaw 2013.

[5] Holtrop, J., Mennen, G. G. J., An Approximated Power Prediction Method, International Shipbuilding Progress, Vol. 29, 1982.

[6] Michalski, J. P., Podstawy teorii projektowania okrętów, Wydawnictwo Politechniki Gdańskiej, Gdańsk 2013.

[7] Molland, A. F., The Maritime Engineering Reference Book, Elsevier 2008.

[8] Schneekluth, H., Bertram, V., Ship design for efficiency and economy, Butterworth Heinemann, Oxford 1998. 